\title{
GESTÃO, VIOLÊNCIA E VANDALISMO ESCOLAR: UMA ANÁLISE DOS TIPOS, PROBLEMAS E ESTRATÉGIAS DE ENFRENTAMENTO
}

\author{
SCHOOL MANAGEMENT, VIOLENCE AND VANDALISM: AN ANALYSIS OF TYPES, \\ PROBLEMS AND COPING STRATEGIES
}

\author{
Osmar Rufino Braga ${ }^{1}$ \\ Michaela Cordeiro Oliari ${ }^{2}$ \\ Sávio Augusto Carvalho Teixeira ${ }^{3}$
}

RESUMO: Um dos maiores problemas enfrentados pelas gestoras e gestores das escolas públicas é a violência escolar, particularmente o vandalismo. Esse problema, cada vez mais, tem sido destacado na grande mídia, que noticia casos complexos envolvendo violência física de estudantes, docentes, gestores e o patrimônio escolar. Este é o alvo do presente trabalho. Trata-se de um artigo que é resultado de uma pesquisa, de cunho qualitativo, em andamento, que está sendo realizada numa escola pública estadual de Parnaíba (PI), com aproximação metodológica ao estudo de caso. Tem como objetivo compreender e analisar os principais problemas que o gestor enfrenta e quais estratégias utiliza diante da violência e do vandalismo que ocorrem no espaço escolar. Para analisar os dados produzidos, amparamo-nos nos estudos de Astor \& Meyer (2001), Laterman (1999), Mafesoli (1987), Barbara Brown (2004), entre outros, procurando fazer um diálogo críticoreflexivo com os dados produzidos na escola. Observamos e constatamos que o papel vital do gestor de uma comunidade escolar, aliado aos demais sujeitos escolares e à comunidade, é fundamental para enfrentar o problema do vandalismo e construir soluções permanentes, melhorando as condutas e o cotidiano escolar. O estudo apontou que há necessidade de profundas reflexões e análises, considerando as diversas dimensões do fenômeno e os modos pelos quais esse mesmo fenômeno se engendra na vida das pessoas e aparta os desejos de reconhecimento, afiliação, visibilidade e afirmação das diferenças, questões vão além das reflexões e soluções apontadas pelo paradigma do direito, da segurança e da racionalidade econômica.

Palavras-chave: Violência escolar, Vandalismo escolar, Gestão escolar.

ABSTRACT: One of the biggest problems faced by public school managers is school violence, particularly vandalism. This problem has been increasingly highlighted in the mainstream media, which reports complex cases involving physical violence by students, teachers, administrators and school assets. This is the aim of the present work. This is an

\footnotetext{
IE-mail: osmarbraga@ufpi.edu.br

22E-mail: oliarimicaelal@gmail.com

3E-mail: savioaugustoct@gmail.com
} 
article that is the result of a research, of a qualitative nature, in progress, which is being carried out in a state public school in Parnaíba (PI), with a methodological approach to the case study. It aims to understand and analyze the main problems that the manager faces and what strategies he uses in the face of violence and vandalism that occur in the school space. To analyze the data produced, we rely on the studies of Astor \& Meyer (200I), Laterman (1999), Mafesoli (1987), Barbara Brown (2004), among others, seeking to conduct a critical-reflective dialogue with the data produced in school. We observed and found that the vital role of the manager of a school community, allied to other school subjects and the community, is fundamental to face the problems of vandalism and build permanent solutions, improving school conduct and daily life. The study pointed out that there is a need for deep reflections and analyzes, considering the different dimensions of the phenomenon and the ways in which this same phenomenon engenders in people's lives and removes the desires for recognition, affiliation, visibility and affirmation of differences, issues go beyond reflections and solutions pointed out by the paradigm of law, security and economic rationality.

Keywords: School violence, School vandalism, School management.

\section{INTRODUÇÃO}

Os atos de violência na escola circunscrevem-se a um conjunto de comportamentos de agressão, imprudentes ou propositais, contra indivíduos e o patrimônio construído (ASTOR \& MEYER, 200I; LATERMAN, 1999). Portanto, a violência escolar é denominada por qualquer ação que seja violenta, comportamentos agressivos, brigas e conflitos interpessoais, e também o vandalismo contra patrimônio escolar, como atos criminosos, destruições e marginalizações, depredação de patrimônio, reunindo ações como quebrar, pichar, sujar, queimar e marcar os espaços, inviabilizando o uso dos mesmos.

\footnotetext{
Sendo assim, não é possível analisar a violência de uma única maneira, torná-la como um fenômeno único. Sua própria pluralidade é a única indicação do politeísmo de valores, da polissemia do fato social investigado. Proponho, então, considerar que o termo violência é uma maneira cômoda de reunir tudo o que se refere à luta, ao conflito, ao combate, ou seja, à parte sombria que sempre atormenta o corpo individual ou social (MAFFESOLI, 1987, p. 15).
}

Esses atos de violência nas escolas e contra as escolas possuem diversos motivos para que se ocorra, desde motivos pessoais dos alunos, reprodução de uma sociedade violenta, sentimento de inferioridade, bullying, tudo isso pode acarretar a um aluno ou a um grupo de alunos a revolta contra a instituição e contra tudo aquilo que ela representa 
para eles. Sendo assim, é necessário que sejam avaliados e investigados os motivos de cunho social e pessoal que levaram os mesmos a tomarem tais atitudes.

Para Éric Debarbieux (2002), no meio escolar, a violência se manifesta sob a forma de incivilidades. Elas não são necessariamente os crimes e delitos do modo como se conhece em cenários mais gerais, mas um conjunto de transgressões a uma ordem previamente estabelecida que acarreta, além dos danos oriundos diretamente do ato infrator, o sentimento de insegurança, desordem e instauração do caos. De acordo com o autor, essas atitudes não podem de fato ser consideradas crimes, no entanto, é sim necessário que haja intervenção de autoridades para que não prossiga com os feitos.

Um lugar ou um patrimônio que está degradado e em condições precárias, sejam elas por conta de ações naturais do tempo ou por vandalismo em si, acabam por encorajar novas atitudes de depredação das pessoas. Para Barbara Brown et al. (2004), espaços degradados transmitem a imagem de que a comunidade não protege ou não pode proteger o lugar, criando oportunidades ao agressor.

Sabemos que os problemas que os gestores enfrentam para conduzir de forma democrática e eficiente uma escola não são poucos, todos os dias os mesmos se encontram em situações complicadas que precisam ser resolvidas de imediato, e uma desses problemas é o vandalismo, que, segundo Costa e Vale (1998, p. II), pode ser definido como sendo a "destruição ou degradação gratuita de objetos, sendo mesmo considerados atos fúteis ou inúteis".

Esse artigo, resultado de uma pesquisa de abordagem qualitativa em andamento, na qual analisamos alguns recortes da produção de dados relativos aos problemas do vandalismo e depredação da escola. Tem como objetivo compreender e analisar os principais problemas que o gestor enfrenta e quais estratégias utiliza frente à violência e ao vandalismo que ocorrem no espaço escolar. Trata-se de uma pesquisa cuja abordagem é qualitativa e usa metodologia do estudo de caso para a produção dos dados. A pesquisa nasceu em diálogo com os estudos e reflexões feitos no contexto do componente curricular “Fundamentos da Gestão Escolar”, no Curso de Pedagogia da UFPI/CMRV, instigando os acadêmicos e acadêmicas a conhecerem de forma mais profunda a realidade da gestão vivida por muitas profissionais da pedagogia, que organizam e dirigem as escolas 
parnaibanas. Tem como indagação básica a seguinte questão: quais os principais problemas vividos pela Escola Estadual “Canto das Margaridas” no que tange ao vandalismo e à depredação e como esses problemas são enfrentados pela mesma no cotidiano escolar?

Nas próximas seções, discorremos acerca da metodologia e desenvolvimento, destacando alguns elementos teóricos, passando em seguida para a análise dos dados recortados para o presente trabalho. Finalizamos com as considerações finais.

\section{METODOLOGIA}

A presente pesquisa é orientada pela abordagem qualitativa, e utilizou o estudo de caso como metodologia para a produção de dados.

A pesquisa qualitativa é definida por Menga Lüdke e Marli André (I986), como aquelas pesquisas que possuem as seguintes características: o ambiente natural como fonte direta de dados e o pesquisador como seu principal instrumento, onde há o contato direto e prolongado do pesquisador com o ambiente e a situação que está sendo investigada; os dados são predominantemente descritivos; há uma preocupação com o processo do que com o produto, procurando compreender como o problema se manifesta nas atividades, nos procedimentos e nas interações cotidianas; tem como foco o significado e a perspectiva dos participantes; a análise é feita com base na indução.

Para Gil (2002, p.54) “o estudo de caso é uma modalidade de pesquisa amplamente utilizada nas ciências biomédicas e sociais”. Desse modo, os pesquisadores dirigiram-se a instituição escolar para produzir os dados acerca do fenômeno da violência e do vandalismo, tomando essa realidade na sua unidade:

Um estudo de caso pode ser caracterizado como um estudo de uma entidade bem definida como um programa, uma instituição, um sistema educativo, uma pessoa, ou uma unidade social. Visa conhecer em profundidade o como e o porquê de uma determinada situação que se supõe ser única em muitos aspectos, procurando descobrir o que há nela de mais essencial e característico. (FONSECA, 2002, p. 33).

Fica compreensível que o estudo de caso, agora referenciando-nos em Lüdke e André (1986, p. 18-20), apresenta algumas características fundamentais, que são destacadas pelas autoras: visam à descoberta; enfatizam a 'interpretação em contexto'; buscam retratar a realidade de forma completa e profunda; usam uma variedade de fontes de informação; 
revelam experiência vicária e permitem generalizações naturalísticas; procuram representar os diferentes e às vezes conflitantes pontos de vista presentes numa situação social; usa uma linguagem acessível.

Como técnica de pesquisa, utilizamos a entrevista, a qual é definida por Marconi e Lakatos (2010) com um encontro entre duas pessoas, a fim de que uma delas obtenha informações a respeito de determinado assunto, mediante a conversação de natureza profissional. O tipo de entrevista realizada de acordo com o propósito entendeu-se como não padronizada. Em concordância com Marconi e Lakatos (2010) na entrevista não padronizada o entrevistador tem a liberdade para desenvolvê-la na direção que visar adequada, de forma a poder explorá-la mais amplamente.

A entrevista foi realizada com a gestora da Escola Estadual "Canto das Margaridas”. A escola está localizada na periferia da cidade de Parnaíba (PI), possui 342 estudantes com idade média de 25 anos e um corpo escolar formado por 39 funcionários, sendo 23 efetivos. Sua construção data dos anos de 1966 e encontra-se atualmente com condições físicas precárias, necessitando de reformas. A última reforma data de 2012. Os 342 estudantes estão divididos em turmas de 6. ao 9. ano e o ensino fundamental e médio de EJA (Educação de Jovens e Adultos).

A análise dos dados recortados da pesquisa para a produção do presente artigo tomou como referência Laurence Bardin (2011), particularmente a análise de conteúdo, definido por ela como

Um conjunto de técnicas de análise das comunicações visando a obter, por procedimentos sistemáticos e objetivos de descrição do conteúdo das mensagens, indicadores (quantitativos ou não) que permitam a inferência de conhecimentos relativos às condições de produção/recepção (variáveis inferidas) destas mensagens (BARDIN, 20II, p. 47).

Usamos as orientações da autora, fazendo um esforço para entender o sentido e significado dos relatos expostos, tentando desvelar o que está por trás das mensagens e fragmentos das opiniões. Da mesma forma, procuramos nos instrumentalizar na organização e classificação do material coletado, fazendo alguns recortes, tentando identificar as categorias relativas ao objeto deste trabalho, como temas geradores e ricos de conteúdo, considerando o processo de inferência e interpretação, elementos que fazem parte da técnica de análise de conteúdo, proposta pela autora. 


\section{VIOLÊNCIA E VANDALISMO NA ESCOLA ESTADUAL “CANTO DAS MARGARIDAS": TIPO E PROBLEMAS}

Pode-se conceber a escola como um ambiente para a transformação social, tendo ela seu papel democrático, socializador e transformador da sociedade. Porém, a violência escolar é uma das principais dificuldades enfrentadas pelos gestores atualmente. É fundamental a construção de uma escola livre de comportamentos inadequados e violentos. Conforme afirma Cardoso et al. (2005), a responsabilidade perpassa todos os atores escolares, ou seja, professores, família, sociedade, políticos e os próprios alunos. A forma como essa construção é implementada promove o sucesso peculiar de cada gestor, não existindo uma fórmula universal a ser ofertada a todas as escolas de forma igualitária (OLIVEIRA, 2009). Por consequência, é vital uma gestão escolar que neutralize formas de violência e vandalismo para que ocorra o processo escolar com potencial êxito na transformação social.

Sposito (1998, p.6o) define a violência como "todo ato que implica a ruptura de um nexo social pelo uso da força. Nega-se, assim, a possibilidade da relação social que se instala pela comunicação, pelo uso da palavra, pelo diálogo e pelo conflito.” A violência é um fenômeno complexo e multicausal, pela especificidade em que ocorre de forma distinta em cada local e é determinada pela experiência de vida, contexto social e tradições socioculturais. Atingem todas as pessoas, grupos sociais ou instituições e por todas é produzida (DE ASSIS e MARRIEL, 20I0).

Nesta parte do trabalho, buscamos apresentar e analisar duas categorias de violência e vandalismo que identificamos no trabalho de produção de dados junto à Escola Estadual “Canto das Margaridas”. Trata-se, pois, de analisar alguns recortes dos dados produzidos no trabalho de pesquisa, ora em andamento.

\section{I.I Bullyng e depredação da escola}

A Escola Estadual "Canto das Margaridas" foi construída com o intuito de ofertar turmas de ensino fundamental maior, do $6 .^{\circ}$ ao $90^{\circ}$ ano, e também a modalidade EJA (ensino de jovens e adultos), para aqueles que se localizavam próximo a ela, em decorrência do crescimento populacional da cidade de Parnaíba. Como já mencionamos, a 
escola possui um total de 342 alunos, todos moradores de bairros próximos à escola, oferecendo um total de i6 turmas nos três turnos. Os alunos mais novos ficam nos turnos da manhã e tarde e os mais velhos, principalmente os de EJA, no turno da noite, por consequência das violências que estavam ocorrendo.

Pudemos verificar nos relatos da gestora da escola, dois tipos de problemas, os quais aparecem na passagem abaixo:

Os meninos mais velhos vinham com muitos problemas e acabavam fazendo bullying com os mais novos, todo dia tinha histórico de bombas na escola, agressões. Tinham alunos com tornozeleiras aqui à tarde, com ordem judicial para estar na escola, senão ficariam presos, convivendo com os menininhos. Conseguimos tirar o EJA do dia e passamos para a noite (GESTORA).

A escola não possuía vigilância em horários de aula nem quando estava fechada, sem atividades. Com isso, sem sequer ter algum cuidado com o patrimônio, a escola ficava à deriva de quem quisesse invadir. Ocorreram invasões, onde se acredita que foram cometidas por ex-alunos, uma vez que eles saberiam onde encontrar chaves, materiais e equipamentos na escola para serem furtados. "Arrombaram a secretaria, pois sabiam que as chaves estavam em na gaveta de uma cômoda de ferro, puxaram, abriram a gaveta, pegaram todas as chaves, abriram toda a escola" (GESTORA).

Como observamos, são destacados dois tipos de violência: o bullyng e a depredação do patrimônio da escola.

Segundo a Lei 13.185, denominada "Programa de Combate à Intimidação Sistemática (Bullying), sancionada em o6 de novembro de 2015

Considera-se intimidação sistemática (bullying) todo ato de violência física ou psicológica, intencional e repetitivo que ocorre sem motivação evidente, praticado por indivíduo ou grupo, contra uma ou mais pessoas, com o objetivo de intimidá-la ou agredi-la, causando dor e angústia à vítima, em uma relação de desequilíbrio de poder entre as partes envolvidas (BRASIL, 2015).

O bullying pode assumir uma natureza verbal, moral, sexual, social, psicológica, física, material e virtual. É muito comum nesse tipo de violência a humilhação e menosprezo, que é despendida contra as vítimas por diversos motivos: porque usa um acessório, um aparelho corretivo; porque é deficiente; porque é negro (a); porque não se 
enquadra no padrão físico (está acima ou abaixo do peso); porque é novato, enfim, por uma lista grande de motivos. Os (as) agressores (as) buscam pessoas "fáceis" e indefesas, a fim de se sentirem poderosas e exercer domínios sobre elas (SOUZA et al., 20II).

Já a Lei № 4.717, de 29 de junho de 1965, considera patrimônio público os bens e direitos de valor econômico, artístico, estético, histórico ou turístico. Portanto, o patrimônio público escolar é o conjunto de bens móveis e imóveis que formam a parte física da escola. Tem valor exponencial e incalculável levado em valimento sua necessidade social e amplitude histórica para o modelo de escola que é vivenciada no ocidente. Para Mazilli (200I), a construção, manutenção e proteção desse patrimônio são de responsabilidade do chefe ou agente a quem está vinculado, seja ele estado, município ou outra instituição.

Sobre a depredação do patrimônio escolar, segundo Galego (2004), este tipo de comportamento não traz benefícios para os agressores, vai muitas vezes contra os seus próprios interesses na medida em que degrada o meio em que eles vivem e são praticados única e exclusivamente pelo gozo e prazer experimentado durante a destruição. Para a autora, esse tipo de atitude diante de uma instituição de ensino e sem um lucro para os agentes, é feito pelo prazer e gozo, como exposto acima, os motivos pelos quais esses grupos têm para realizar tais atitudes, são muitos, e na maioria das vezes, podem ser reações tomadas a partir de uma ação anterior de violência praticada com os mesmos.

Pelo relato feito acima pela gestora, podemos observar que os tipos de violência na escola vão além dos vandalismos, destacando-se os problemas que atravessam a relação entre alunos. Eda Góes (2002) nos ensina que existem tantas formas de violência quantas são as maneiras de nos relacionarmos socialmente. Contudo, no contexto escolar, o que está prevalecendo nessa escola são as violências verbais e a depredação do patrimônio, sem quaisquer cuidados com a instituição, vandalizando tudo aquilo que foi feito para os próprios alunos e comunidade.

A gestora relatou também que os problemas que enfrentou teve origem na gestão anterior a ela, onde já ocorriam diversas violências contra a instituição: "Quando eu entrei aqui em 2017, em abril de 2017, a escola estava sofrendo muitos assaltos, então quase tudo que ela tinha foi roubado, caixa de som, bola, botijão de gás, panelas, lâmpadas [...]” 
(GESTORA). Vemos, assim, que o gestor escolar tem grande responsabilidade pela ambiência física e patrimonial da escola e seu papel tornou-se mais complexo, uma vez que se assume como mediador de conflitos e educador não apenas do que tange à questão pedagógica, é também um educador do uso e cuidado com o espaço e o patrimônio público.

Atualmente é vivenciada na realidade brasileira uma mudança nos papeis relacionados à antiga figura de diretor escolar, hoje intitulado gestor escolar, com essa modificação também é alterado o conceito dado a esse profissional. Conforme retrata Lück (2009, p.22), gestores escolares:

[...] são os profissionais responsáveis pela organização e orientação administrativa e pedagógica da escola, da qual resulta a formação da cultura e ambiente escolar, que devem ser mobilizadores e estimuladores do desenvolvimento, da construção do conhecimento e da aprendizagem orientada para a cidadania competente. Para tanto, cabe-lhes promover a abertura da escola e de seus profissionais para os bens culturais da sociedade e para sua comunidade. Sobretudo devem zelar pela constituição de uma cultura escolar proativa e empreendedora capaz de assumir com autonomia a resolução e o encaminhamento adequado de suas problemáticas cotidianas, utilizando-as como circunstâncias de desenvolvimento e aprendizagem profissional.

Dessa forma, pode-se entender que o papel do gestor escolar vai além da administração do corpo docente e discente, o profissional responsável pela gestão escolar também deve promover cidadania e cultura para a sociedade e a comunidade escolar, como a abertura da escola para a promoção de atividades de cunho social. Como a ele também é atribuído à necessidade de procurar meios para a solução de problemáticas que afetem o desenvolvimento da escola.

Conforme afirma Dias (1998), existem três aspectos para conceituar o gestor escolar: a) o gestor como autoridade escolar, carrega todas as responsabilidades e atribuições, se faz responsável por tudo que acontece dentro da instituição, representa a escola em algumas ocasiões como em solenidade, confere certificados e diplomas. Nessas ocasiões ele não age como um simples administrador, mas sim como uma autoridade escolar; b) o gestor educador, nesse caso existe a necessidade do conhecimento da prática docente, seria indicado que o gestor tivesse uma experiência docente prévio, porém não indicando que ele deve exercê-la enquanto gestor; c) o gestor como administrador que, segundo Zabot (1986), a escola tem objetivos a atingir, e ao gestor compete assumir a 
liderança para a organização do trabalho, coordenação dos esforços e avaliação dos resultados, entre outras, pois enquanto o gestor se envolve com estas atividades, estará desempenhando sua função de administrador.

Com toda a dimensão que cerca as competências do profissional responsável pela gestão da educação em cada unidade escolar, uma das necessidades oriundas do gestor, alvo da pesquisa, foi o combate à violência e ao vandalismo que ocorre na escola que administra.

\subsection{Arrombamentos, roubos de equipamentos e materiais escolares}

Outro tipo de violência identificado é o roubo de equipamentos e materiais escolares, apresentado pela gestora no relato abaixo:

No início de 2018 ajeitamos a escola toda para começar as aulas, no primeiro dia de aula estava um rebuliço aqui, as salas tinham latas de usuário de drogas que arrombaram a sala de educação artística, jogaram os papeis e quadros fora, tinha cola e papel espalhado em toda a escola. Saímos daqui no sábado à tarde e deixamos tudo arrumado, quando foi segunda feira de manhã estava desse jeito, as salas, fizeram até necessidades em cima da mesa, [...] fizemos o boletim de ocorrência e conversamos com os alunos, chamamos os alunos no pátio e conversamos, e não aconteceu mais isso. Esse ano graças a Deus, eu fiquei morrendo de medo de acontecer à mesma coisa no primeiro dia de aula, mas não aconteceu (GESTORA).

Foram roubados computadores, lâmpadas, mesas, cadeiras, materiais pedagógicos, como folhas, canetas, cadernos, e etc. Não só roubaram esses objetos, segundo a gestora, ocorreu também a depredação de alguns materiais, salas de aula e demais dependências da escola.

Para analisar o relato acima, convém recuperar o conceito de violência escolar, trabalhado por Ristum (2010), que desdobra o conceito em três tipos: violência na escola, violência da escola e violência contra a escola. A primeira, violência na escola, é caracterizada pelas agressões que envolvem diferentes atores escolares, seja eles violência entre alunos, violência de alunos contra professores, de alunos contra o patrimônio da escola (depredação) e diversas outras modalidades. A segunda, violência da escola “[...] destaca uma forma de violência própria ao ambiente institucional, à violência simbólica"; a terceira modalidade de violência se faz presente como norteadora na construção da referida pesquisa, a violência contra a escola. Essa modalidade de violência, muito conhecida do 
Brasil, é praticada tanto por alunos como por grupos alheios aos espaços escolares. Ocorre geralmente em escolas públicas mal equipadas e mal conservadas, que sofrem grandes ataques a sua estrutura física como depredações, roubos e arrombamentos.

Considerando o exposto pela autora acima citada, situamos o arrombamento de escolas, roubos de equipamentos e de materiais no tipo de violência contra a escola. Segundo Ristum (2010), a escola pública sofre grande perdas e prejuízos com essas ações e elas são muito frequentes no cotidiano escolar. A autora atribui o crescimento desse tipo de violência na escola a sua desorganização, a falta quase que permanente de professores, a forma pouco atraente na condução das aulas, distanciamento da escola em relação à comunidade.

Essa modalidade de violência, também pode ser analisada à luz do pensamento de Guimarães (2005, p. 19,20), que afirma que

A escola é um dos alvos preferidos, pois ela contraria todos os seus pressupostos, isto é, se diz democrática, mas não o é; diz que prepara para a vida, mas não o faz; é o lugar do novo, mas propaga o velho. [...] O que significa hoje frequentar uma escola com professores mal remunerados, com um número insuficiente de funcionários e instalações precárias? Ser aluno de uma escola deste tipo é um indicador social, pois pertencer a ela é mostrar as condições a que se está submetido.

Verificamos que há uma relação estreira entre a escola precária, desorganizada, com professores precarizados, desvalorizados, de baixa autoestima, desinteressados, com tripla jornada de trabalho na sua maiori, distante da comunidade, etc., e a violência praticada contra a escola. Podemos avaliar o ataque e a agressão à escola como uma reação a um determinado modelo de escola, de ensino, vazia de referências, desanimada, abandonada pelo estado e pela sociedade? Concordamos que sim. A escola de hoje, inserida e vítima do processo de desvalorização, precarização e abandono pelo estado brasileiro, perdeu o reconhecimento social da relevância da educação formal por parte da sociedade. Nesse sentido, é apropriado refletir sobre o que diz Da Mata (1982), quando afirma que o quebraquebra é um grito e tem como objetivo não modificar o Estado, mas obter um reconhecimento através deste ato violento que anuncia a voz daqueles indivíduos destituídos, que as elites consideram de "segunda classe”. Então, em última análise, 
podemos dizer que existe primeiro uma violência que é institucional, ou seja, tem a própria escola (precária, desvalorizada, despreparada, sem referência, penalizada, etc.), seu gestor maior, que é estado brasileiro, como violadora dos direitos a uma educação de qualidade; uma escola que não cumpre seus objetivos humanos sociais e culturais.

\section{A ESTRATÉGIA DE ENFRENTAMENTO DAS VIOLÊNCIAS}

Buscamos saber como a escola, através de sua representante maior, vem enfrentando a os tipos de violência aqui analisadas.

A gestora relata que vem enfrentando os problemas ligados às violências, trazendo e implementando na escola projetos sociais, estreitando os laços entre a escola e a comunidade; pediu apoio das famílias dos estudantes, do corpo docente e demais funcionários da instituição.

A escola era muito fechada, ninguém deixava os alunos usarem a quadra, ninguém deixava fazer atividades aqui dentro da escola. Aí nós abrimos a escola para a comunidade e projetos sociais. Temos a escolinha de futebol, trouxemos uma banda para a escola, a banda precisava de um lugar e juntamos o útil ao agradável, os alunos queriam, eles gostam da banda, então a trouxemos para cá. E assim a escola sempre tem gente para cuidar e evitar que outras pessoas entrem aqui e destruam algo (GESTORA).

Uma das grandes mudanças relembradas pela gestora é relativa à visibilidade positiva que a escola está recebendo na cidade, com as mudanças em relação as funcionalidades do estabelecimento. A instituição vem recebendo diversas visitas de estudantes universitários e pessoas autônomas, com iniciativas e trabalhos sociais que beneficiam a comunidade escolar, trazendo melhorias na participação dos pais e dos alunos. Uma das iniciativas rememoradas pela profissional foi a seguinte:

Uma das coisas que foi muito positiva foi o natal branco, um jovem ano passado pediu para fazer no dia 25 de novembro um natal branco. Ele é de fortaleza e se juntou com um grupo de universitários da UESPI e distribuíram 200 cestas com 200 brinquedos, fizeram atividades, separaram as crianças por faixa etária, botaram coletinho, passaram o dia inteiro brincando com as crianças, deram lanche, fizeram atividade e no final cada um tinha sua cesta básica com seu nome, com brinquedo, foi um marco histórico para a escola. (GESTORA) 
A partir dessas ações da gestora e do envolvimento da comunidade escolar, a instituição começou a ter apoio e auxílio, podendo assim criar uma base firme para iniciar suas mudanças. Quando o corpo docente e a comunidade, principalmente as famílias dos estudantes, começaram a notar as modificações e melhorias que a escola estava vivenciando, outro território escolar foi sendo construído e percebido, desaparecendo os problemas relativos à violência e ao vandalismo na escola.

Observamos que o enfrentamento às diversas formas de violência na escola não é resolvido, necessariamente, como muitos tentam nos fazer crer, pela via da segurança, do direito e da razão. É preciso atentar, como bem nos lembra Guimarães (2005), que a violência escolar é ambígua, necessitando ser compreendida em suas singularidades e modos específicos de sua manifestação.

A escola, considerada como lugar apropriado para a construção do saber, da condição humana, da formação da cidadania e valores sociais, por um lado, está enfrentando os conflitos contemporâneos sem estar preparada para assegurar o lugar de feixes de relações sociais e entrelaçadas de confiabilidade (GIDDENS, I991, p. I05) e é por consequência disso, que aqueles com maior conhecimento e disposição, devem tomar a frente e terem atitudes que enfrentem e altere as diversas formas de violência, fazendo com que a formação da cidadania tenha êxito dentro e fora da escola.

Com o apoio que a gestora da escola conseguiu conquistar de sua comunidade, de seus funcionários e estudantes, e as ações e estratégias implementadas a escola mostrou que é possível construir caminhos e colocar o fazer pedagógico, ação fundante da escola, noutro lugar, ressignificando o espaço e o patrimônio público. A gestora, sua luta e a capacidade de enfrentamento dos conflitos, mostraram que é possível conquistar e construir um novo lugar para escola, como destaca Ferreira (2013, p. 15), um lugar onde a escola pode ser

[...] um lugar da estética, da empatia, do respeito, no qual a educação [...] seja valorizada pela escola como processo de promoção, proteção, defesa, aplicação e atenção humanizada às pessoas e grupos sociais e uma realidade concreta na vida cotidiana, no imaginário e representações dos sujeitos de direitos e de responsabilidades individuais e coletivas. 
Porém, sabemos que, para que essa escola seja uma realidade em nosso meio, é necessário que tomar consciência e assumir o desafio de que as mudanças nesse contexto depedem do reconhecimento e valorização social da relevância da educação formal por parte do estado e da sociedade.

\section{CONSIDERAÇÕES FINAIS}

A violência está inserida na nossa sociedade há muito tempo, e ela pode ser apresentada de diversas formas, como foi exposto de forma recortada nesse estudo, no entanto, nas escolas, as formas de violência e vandalismo, acarretam problemas não só pessoas para as pessoas envolvidas, mas também, problemas que interferem no ensino de uma instituição de ensino, envolvendo e prejudicando alunos e toda a comunidade escolar.

O (a) gestor (a) de uma escola precisa conhecer sua realidade, seus alunos, sua comunidade e seu corpo docente, para assim poder tomar medidas preventivas e mediadoras diante de todo e qualquer problema, principalmente aqueles que irão atravancar o aprendizado e o desenvolvimento dos seus discentes.

Com isso, pela análise dos aspectos desenvolvidos nesse texto, percebemos o papel vital do gestor escolar na transformação da realidade escolar. Observamos que o gestor pode fazer um pacto coletivo e colocar em movimento diferentes atores sociais e assim enfrentar os problemas ligados à violência na escola, buscar entender esses problemas nas suas especificidades e modulações e deste modo construir caminhos de enfrentamento, de paz e valorização da educação como um todo. Somente assim pode construir uma escola segura, que cumpra eu papel socializador, democrático e transformador, garantindo que a escola seja um espaço coletivo de construção e partilha de conhecimentos.

Constatamos que a mudança no funcionamento da escola pode trazer resultados significativos na vida escolar. A mudança e a adequação dos alunos por faixa etária e modalidade de ensino trouxeram uma diminuição nos casos de violência e do bullying que ocorriam na instituição. E que a implementação de pequenas ações articuladas pode produzir grandes resultados.

Finalmente, queremos afirmar que este texto não teve a pretensão de apresentar fórmulas para a solução da violência e do vandalismo escolar, tampouco um resultado 
definitivo e não passível de mudança da realidade estudada. Procurou fazer uma provocação a fim de indicar que é necessário aprofundar os estudos sobre a violência escolar, caminhando para além de sua compreensão sob o paradigma do direito, da segurança e da racionalidade econômica, referenciais que têm mostrado seus limites na resolução dos problemas ligados aos diversos tipos de violência escolar.

\section{REFERÊNCIAS}

BARDIN, L. Análise de conteúdo. São Paulo: Edições 7o, 2011.

BRASIL. Lei no 13.185, de 6 de novembro de 2015. Institui o Institui o Programa de Combate à Intimidação Sistemática (Bullying). Diário Oficial da União: seção I, Brasília, DF, ano CLII 213, p. I, 9 nov. 2015. Disponível em: 〈http://www.planalto.gov.br/ccivil_03/_Ato20152018/2015/Lei/Li3185.htm >

DE ASSIS, Simone Gonçalves; MARRIEL, Nelson de Souza Motta. 2. Reflexões sobre Violência e suas Manifestações na Escola. Impactos da violência na escola: um diálogo com professores, 2010.

DEMO, Pedro. Metodologia Científica em ciências sociais. 3. ed. rev. e ampl. 13. São Paulo: Atlas, 2009.

DA MATA, Roberto. As raízes da violência no Brasil. In: Violência Brasileira. São Paulo: Brasiliense, 1982.

DIAS, J. A. Gestão da Escola. In: MENEZES, J.G. C., org. Estrutura e funcionamento da Educação - Leituras. São Paulo: Pioneira, 1998.

FERREIRA, Maria de Fatima Andrade. A banalização da violência na Escola. Disponível em: https://educere.bruc.com.br/arquivo/pdf2013/10676_5790.pdf. Acesso em 19/o6/2019.

FONSECA, J. J. S. Metodologia da pesquisa científica. Apostila, Fortaleza: UEC, 2002.

GALEGO, Carla. Violência nas escolas: Representação social dos mass media. Disponível em https://aps.pt/wp-content/uploads/2017/o8/DPR4628bcob8d9c4_I.pdf. Acesso em 19/06/2019.

GIL, Antônio Carlos. Como elaborar projetos de pesquisa. - 4. ed. - São Paulo: Atlas, 2002. 
JOTZ, Maria Eunice Viana. O Combate à intimidação sistemática sob a tutela da constituição federal: "Bullying" é questão de direito. 2016.

LEI № 4.717, de 29 de junho de 1965. Patrimônio Público. Disponível em: http://www.planalto.gov.br/ccivil_03/leis/L4717.htm. Acesso em: 13/o6/19.

Lück, Heloísa. Dimensões de gestão escolar e suas competências. Curitiba: Editora Positivo, 2009.

LÜDKE, Menga e ANDRÉ, Marli E. D. A. Pesquisa em educação: abordagens qualitativas.

São Paulo: EPU, 1986.

MACORE, Alfredo. Patrimônio publico. Disponível em: https://pt.slideshare.net/sergiomacore/patrimonio-publico-51913550. Acesso em 13/o6/19. MARCONI, M. de A.; LAKATOS, Eva Maria. Fundamentos de metodologia cientifica. 7 edição. Rio de Janeiro: Editora Atlas, 20 o.

OLIVEIRA, José Eduardo Costa de. As ações das escolas, através de seus gestores, no processo de enfrentamento da violência escolar. Tese de Doutorado. Universidade de São Paulo, 2009.

RISTUM, Marilena. Violência na escola, da escola e contra a escola. . Impactos da violência na escola: um diálogo com professores, 2010.

SOUZA, Christiane; ALMEIDA, Léo Cesar. Bullying em ambiente escolar. Enciclopédia Biosfera: Centro Científico Conhecer. Goiânia, v.7, n.ı2, nov. 2011 p. I79.

SPOSITO, M. P. A instituição escolar e a violência. Cadernos de Pesquisa, p.6o, 1998. 